\title{
First report on cutaneous infectious granuloma caused by Schizophyllum commune
}

\author{
Lidi $\operatorname{Tian}^{1 \dagger}{ }^{\dagger}$ Yunzhu Mu${ }^{1 \dagger}$, Hao Zhang ${ }^{2^{*}} \mathbb{D}$, Xiaocui Su${ }^{1}$, Chuan Yang ${ }^{1}$, Xianzhu Shu ${ }^{1}$ and Defu Qing ${ }^{1}$
}

\begin{abstract}
Background: Schizophyllum commune, a basidiomycetous fungus, is a common invader of rotten wood. This fungus rarely causes mycotic disease in humans, especially cutaneous infection. In this paper, we describe the first case of cutaneous granuloma caused by S. commune in a Chinese woman.

Case presentation: A 25-year-old female with a two-year history of erythema, papules, nodules, and scales on her sole of left foot was presented to our outpatient center. Samples were obtained by the scraping of lesion and for light microscopy. Hyphae were observed by microscopic examination. We carried out a skin tissue biopsy, which showed multiple granulomatous nodules. Biopsy specimens were also inoculated onto media. After being cultured on SDA at $27^{\circ} \mathrm{C}$ for 7 days, spreading-woolly-white colonies grew on the inoculation sites of media containing chloramphenicol only and there's no other colonies grew. S. commune was identified by morphology methods, biochemical tests, and PCR sequencing. Pathological findings also aided in diagnosing cutaneous fungal granuloma. Oral itraconazole was applied. After 1 month of therapy, rashes on her left foot and pain were improved.
\end{abstract}

Conclusion: We describe the first case of cutaneous granuloma caused by Schizophyllum commune, which illustrates the importance of recognizing uncommon pathogenic fungal infections.

Keywords: Cutaneous granulomas, Itraconazole, Schizophyllum commune

\section{Background}

Schizophyllum commune is a common fungal species, which belongs to Eukaryota, Opisthokonta, Fungi, Dikarya, Basidiomycota, Agaricomycotina, Agaricomycetes, Agaricomycetidae, Agaricales, Schizophyllaceae, Schizophyllum. This fungus colonizes diverse trees and rotting woods worldwide [1-3]. S. commune has also long been regarded as nonpathogenic to humans $[4,5]$. Recently, an increasing number of cases related to $S$. commune infection has been reported. Most reports are associated with allergic bronchopulmonary mycosis (ABPM) after inhaling the spores of $S$. commune $[1,2$, 6]. Infection in deep tissues, such as the sphenoid sinus, maxillary sinus, and brain, has also been recently

\footnotetext{
* Correspondence: dr.zhanghao@126.com

+Lidi Tian and Yunzhu Mu contributed equally to this work.

${ }^{2}$ Department of Dermatology, Shenzhen Baoan Central Hospital and the 5th Affiliated Hospital of Shenzhen University Health Science Center, Shenzhen, China

Full list of author information is available at the end of the article
}

reported [2, 7-9]. To our knowledge, the cutaneous infection caused by S. commune has not been reported yet.

\section{Case presentation}

A 25-year-old female with a two-year history of erythema, papules, nodules, and scales on her sole of left foot was presented to our outpatient center. She has no history of autoimmue disease and untreated with immunosuppressive therapy. Considering her pregnancy, she was not given treatments for 1 year. The left foot skin lesion on the medial and lateral margins and on the fourth toe dorsum became enlarged with evident pain after more than 1 year (Fig. 1a and b). Approximately 1 month before visiting our department, she received treatment ineffectively in a local clinic, and the diagnosis was unclear.

Samples were obtained by the scraping of lesion and for light microscopy. Hyphae were observed by microscopic examination (Fig. 2). 


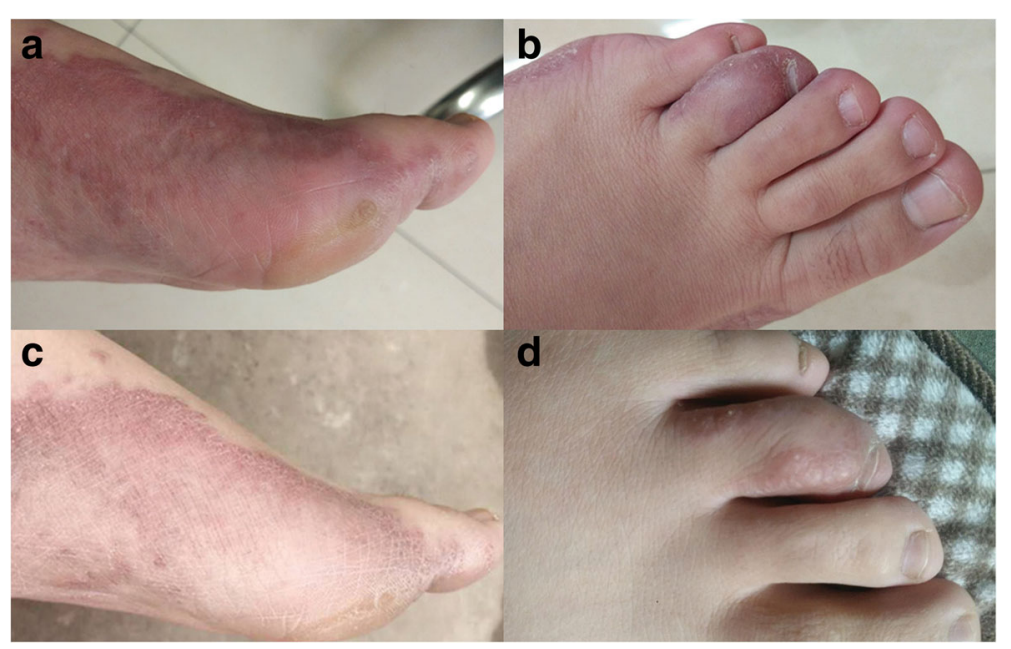

Fig. $1(\mathbf{a}, \mathbf{b})$ Sole of left foot exhibits erythema, papules, nodules, and scales. The fourth toe dorsum is also infected. (c, d) Foot lesions regressed after 1 month of treatment

We carried out a skin tissue biopsy, which showed multiple granulomatous nodules (Fig. 3a). The Ziehl-Neelsen stain was negative. Periodic acidSchiff (PAS) and Grocott methenamine silver (GMS) staining were carried out two times. Results were also negative. Biopsy specimens were also inoculated onto two kinds of media: Sabouraud's dextrose agar (SDA), where one of which contained chloramphenicol and cycloheximide, and the other one contained chloramphenicol only. After being cultured on SDA at $27{ }^{\circ} \mathrm{C}$ for 7 days, spreading-woolly-white colonies grew on the inoculation sites of media containing chloramphenicol only and there's no other colonies grew (Fig. 3b). The colonies produced an unpleasant smell like biogas. No colony was observed on the media with chloramphenicol and cycloheximide. Clamp connections, spicules, tear-like

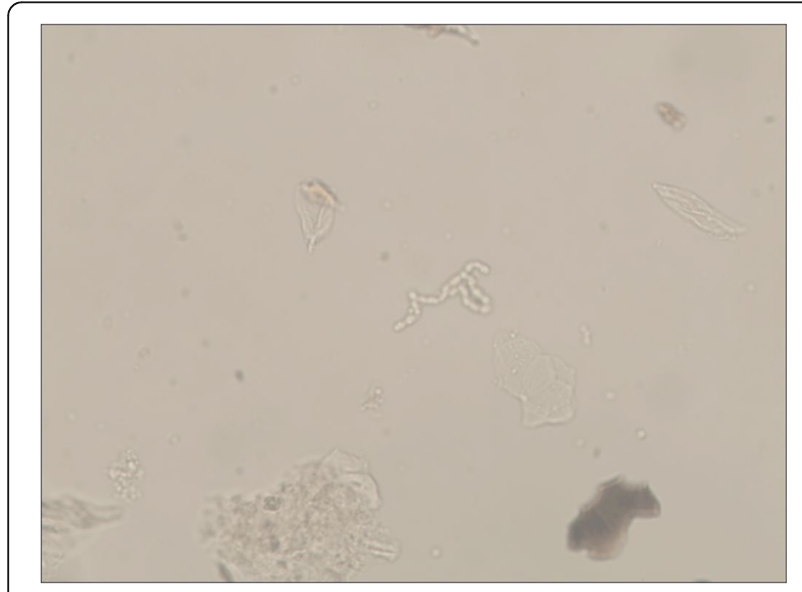

Fig. 2 Hyphae were observed by microscopic examination (400x)

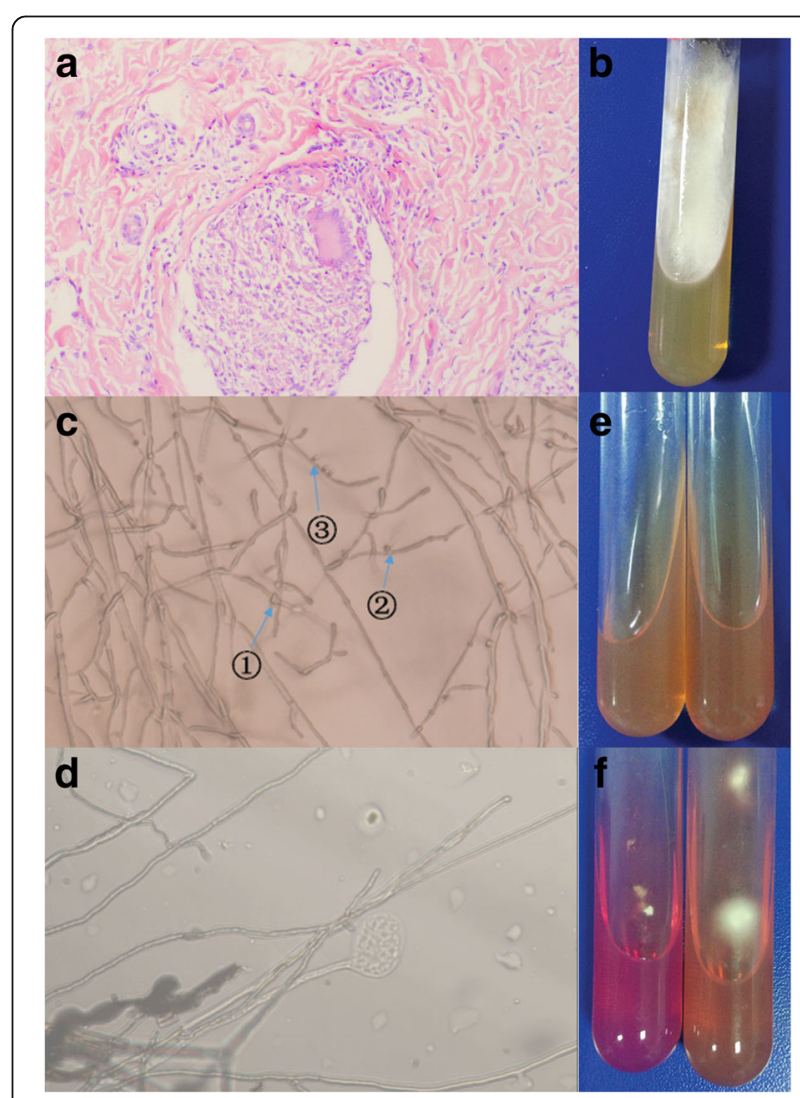

Fig. 3 a Hematoxylin-eosin (H\&E) stain for pathology study showed multiple granulomatous nodules $(\times 200)$. b When cultured on

Sabouraud's dextrose agar, spreading-woolly-white colonies grew on the media containing chloramphenicol only. $\mathbf{c}$, d Clamp connections (1), spicules (2), tear-like secretions(3), and medusa-like isomers were observed on the slide culture at $27^{\circ} \mathrm{C}$ after 3 days (400X). e, $\mathbf{f}$ Urease activity test before and after cultivation: isolated strain $(+)$, Trichophyton rubrum standard strain (-) 
secretions, and medusa-like isomers were observed on the slide culture at $27{ }^{\circ} \mathrm{C}$ after 3 days (Fig. 3c and d). Urease activity tests were also performed. Trichophyton rubrum standard strain and the isolated strain were cultured on urease media at $27{ }^{\circ} \mathrm{C}$ for 7 days. The T. rubrum standard strain was negative, whereas the isolated strain turned red (Fig. 3e and $\mathrm{f}$ ).

Sequencing of large subunit rDNA was performed by using the E.Z.N.A. ${ }^{\text {ma }}$ Fungal DNA Mini Kit (Omega Biotek, USA). We utilized set primers for the region of internal transcribed spacer (ITS) and performed PCR. The PCR primers were $\mathrm{ITS}_{1}$ : 5'-TCCGTAGGTGAACCTGCGG-3' and ITS 5 '-TCCTCCGCTTATTGATATGC-3'. ${ }^{\prime}$ The PCR-amplified DNA was matched with that of $S$. commune (Nos. KP 326677.1 and KP 004975.1) with a homology of $100 \%$. After identification, the sequence was submitted to the GenBank (MF 495704).

Pathological finding and mycological examination indicated a cutaneous granuloma caused by $S$. commune. Oral itraconazole $(100 \mathrm{mg})$ was applied twice a day. The rashes on the left foot and the pain regressed after 1 month of treatment (Fig. 1c and d). Follow-up is currently under way.

\section{Discussion and conclusions}

To our knowledge, fungal granuloma is caused by a wide variety of fungi, such as Coccidioides, Histoplasma, Blastomyces, Cryptococcus, T. rubrum, and T. mentagraphytes, but some less known fungi have been recently documented as causes of fungal granuloma [10]. In the past, S. commune was regarded as a rare human pathogen. Since 1950 when Kligman reported the first case of onychomycosis caused by $S$. commune, this fungus has emerged as an increasingly important pathogen for clinical disease [11]. We conducted a literature review through PubMed and found that $S$. commune is an opportunistic pathogenic fungus that can cause sinusitis and ABPM mostly [3, $12]$, as well as rarely isolated from patients with onychomycosis, palate ulceration $[11,13]$. Table 1 shows the clinical spectrum of fungal disease caused by $S$. commune and country-wise distribution of clinical cases. Cutaneous and subcutaneous infections caused by $S$. commune have not been previously reported.

In our case, colonies grew on the inoculation sites of media with no other colonies grew and antifungal therapy only was effective, which can be excluded the possibility of contamination. We describe the first case of cutaneous granuloma caused by S. commune, which illustrates the importance of recognizing uncommon pathogenic fungal infections.
Table 1 Clinical spectrum of disease due to Schizophyllum commune and country-wise distribution of clinical cases $(n=99)$

\begin{tabular}{|c|c|c|}
\hline Mycosis (No. of case) & $\begin{array}{l}\text { Country } \\
\text { (No. of cases) }\end{array}$ & References \\
\hline \multirow[t]{12}{*}{ Sinusitis (34) } & Austria (5) & {$[14,15]$} \\
\hline & USA(3) & {$[8,16]$} \\
\hline & Colombia(3) & [17-19] \\
\hline & France (3) & [20-22] \\
\hline & Serbia (2) & {$[23,24]$} \\
\hline & India(2) & {$[25,26]$} \\
\hline & U.K. (1) & {$[27]$} \\
\hline & Japan (7) & [28-30] \\
\hline & Australia (1) & {$[31]$} \\
\hline & New Zealand(2) & {$[5,32]$} \\
\hline & South Korea(3) & {$[2,33]$} \\
\hline & China(2) & {$[34,35]$} \\
\hline \multirow[t]{2}{*}{ ABPM (30) } & Japan(29) & {$[3,5,36-49]$} \\
\hline & India $(1)^{a}$ & {$[50]$} \\
\hline Bronchial mucoid impaction (8) & Japan(8) & {$[38,45,51-56]$} \\
\hline \multirow[t]{2}{*}{ Pulmonary fungal ball (2) } & North America(1) & {$[57]$} \\
\hline & India(1) & {$[50]$} \\
\hline Schizophyllum asthma(2) & Japan(2) & {$[58]$} \\
\hline $\begin{array}{l}\text { Pulmonary infiltrate } \\
\text { plus eosinophilia (1) }\end{array}$ & Japan(1) & {$[38]$} \\
\hline Chronic eosinophilic pneumonia (1) & Japan(1) & {$[59]$} \\
\hline Honeycomb lung (1) & Japan(1) & {$[60]$} \\
\hline Bronchogenous cyst (1) & Serbia (1) & {$[61]$} \\
\hline Pulmonary nodules (1) & Taiwan (1) & {$[62]$} \\
\hline \multirow[t]{3}{*}{ Other pulmonary mycoses (11) } & $\operatorname{Iran}(7)$ & {$[63]$} \\
\hline & Japan (3) & {$[38]$} \\
\hline & Italy (1) & {$[64]$} \\
\hline \multirow[t]{2}{*}{ Brain abscess (2) } & USA (1) & {$[9]$} \\
\hline & Austria (1) & {$[15]$} \\
\hline Ulceration of the palate (1) & Colombia (1) & [13] \\
\hline Otitis externa (1) & Slovenia (1) & {$[65]$} \\
\hline Fatal Empyema Thoracis (1) & Hong Kong (1) & {$[66]$} \\
\hline Onychomycosis (1) & USA (1) & {$[11]$} \\
\hline Meningitis (1) & Brazil (1) & {$[67]$} \\
\hline
\end{tabular}

anclude only one case, but the patient has the allergic broncho-pulmonary mycosis and bronchial mucoid impaction at the same time

\section{Abbreviations}

ABPM: Allergic bronchopulmonary mycosis; GMS: Grocott methenamine silver; ITS: Internal transcribed spacer; PAS: Periodic acid-Schiff; PCR: Polymerase chain reaction; S. commune: Schizophyllum commune; SDA: Sabouraud's dextrose agar, $T$. mentagraphytes: Trichophyton mentagraphytes; T. rubrum: Trichophyton rubrum

\section{Acknowledgments}

We thank Prof. Lin Wang from West China Hospital of Sichuan University for pathologic diagnosis assistance. 


\section{Fundings}

This work was supported by local city-school cooperation project (NSMC20170418) and the Project Q15005 of Youth innovation in medical research of Sichuan Province.

\section{Availability of data and materials}

Data sharing is not applicable to this article as no datasets were generated or analysed during the current study.

\section{Authors' contributions}

LT and YM conceptualized, collected and interpreted the clinical data, and wrote the manuscript. $\mathrm{HZ}$ designed, interpreted the clinical data and wrote the manuscript. $X \mathrm{CS}, \mathrm{CY}$, and $\mathrm{XZS}$ revised the manuscript critically for important content. DQ carried out the microbiological examination and nucleotide sequencing. All authors read and approved the final manuscript

\section{Ethics approval and consent to participate}

Not applicable.

\section{Consent for publication}

Written informed consent was obtained from the individual patient described in this report. A copy of the written consent is available by request.

\section{Competing interests}

The authors declare that they have no competing interests.

\section{Publisher's Note}

Springer Nature remains neutral with regard to jurisdictional claims in published maps and institutional affiliations.

\section{Author details}

'Department of Dermatology, Affiliated Hospital of North Sichuan Medical College, Nanchong, China. ${ }^{2}$ Department of Dermatology, Shenzhen Baoan Central Hospital and the 5th Affiliated Hospital of Shenzhen University Health Science Center, Shenzhen, China.

\section{Received: 24 January 2018 Accepted: 7 June 2018}

\section{Published online: 26 June 2018}

\section{References}

1. Ren $Q$, Wan $L$, Ju Y, et al. Animal experimental study of the pathogenicity of Schizophyllum commune. J Clin Dermatol. 2011;40(10):587-91.

2. Won EJ, Shin $\mathrm{JH}$, Sang $\mathrm{CL}$, et al. Molecular identification of Schizophyllum commune as a cause of allergic fungal sinusitis. Ann Lab Med. 2012;32(5):375-9.

3. Kobayashi H, Taira T, Wakuda $K$, et al. A favorable clinical effect of an expectorant in allergic bronchopulmonary mycosis caused by Schizophyllum commune. Respiratory Med Case Rep. 2016;19:54-7.

4. Unno H, Kamei K, Honda A, et al. A murine model of pulmonary basidiomycosis by Schizophyllum commune. J Infect Chemother. 2005; 11(3):136-40.

5. Kamei $\mathrm{K}$, Unno H, Nagao $\mathrm{K}$, et al. Allergic bronchopulmonary mycosis caused by the basidiomycetous fungus Schizophyllum commune. Clin Infect Dis. 1994;18(3):305-9.

6. Tanaka H, Takizawa K, Baba O, et al. Basidiomycosis: Schizophyllum commune osteomyelitis in a dog. J Vet Med Sci. 2008;70(11):1257-9.

7. Roh ML, Tuazon CU, Mandler R, et al. Sphenocavernous syndrome associated with Schizophyllum commune infection of the sphenoid sinus. Ophthalmic Plast Reconstr Surg. 2005;21(1):71-4

8. Kern ME, Uecker FA. Maxillary sinus infection caused by the homobasidiomycetous fungus Schizophyllum commune. J Clin Microbiol. 1986;23(6):1001-5

9. Rihs JD, Padhye AA, Good CB. Brain abscess caused by Schizophyllum commune: an emerging basidiomycete pathogen. J Clin Microbiol. 1996; 34(7):1628.

10. Li G. The research progress of fungal granuloma. Chin J Mycol. 2014; 9(6):373-6.

11. Kligman AM. A Basidiomycete causing onychomycosis. illust. 1950;14(1):67-70
12. Seki M, Ohno H, Gotoh K, et al. Allergic bronchopulmonary mycosis due to co-infection with aspergillus fumigatus, and Schizophyllum commune. Idcases. 2014;1(1):5-8.

13. Restrepo A, Greer DL, Robledo M, et al. Ulceration of the palate caused by a basidiomycete Schizophyllum commune. Sabouraudia. 1973;11(3):201.

14. Buzina W, Lang-Loidolt D, Braun $H$, Freudenschuss $K$, Stammberger $H$. Development of molecular methods for identification of Schizophyllum commune from clinical samples. J Clin Microbiol. 2001;39:2391-6.

15. Hoenigl M, Aspeck E, Valentin T, et al. Sinusitis and frontal brain abscess in a diabetic patient caused by the basidiomycete Schizophyllum commune: case report and review of the literature. Mycoses. 2013;56(3):389-93.

16. Rosenthal J, Katz R, DuBois DB, Morrissey A, Machicao A. Chronic maxillary sinusitis associated with the mushroom Schizophyllum commune in a patient with AIDS. Clin Infect Dis. 1992;14:46-8.

17. Sigler L, Estrada S, Montealegre NA, et al. Maxillary sinusitis caused by Schizophyllum commune and experience with treatment. J Med Vet Mycol. 1997:35(5):365-70.

18. Jiménez R, Rodríguez C, Arango M, et al. Sinusitis por Schyzophyllum commune: informe de nueve casos. Infectio. 2002:6:108.

19. Castro LÁ, Álvarez MI, Martínez E. Case report of Schizophyllum commune sinusitis in an immunocompetent patient. Colombia Med. 2010;41(1):71-5.

20. Marlier S, De Jaureguiberry JP, Aguilon P, et al. Chronic sinusitis caused by Schizophyllum commune in AIDS. Presse Med. 1993;22(23):1107.

21. Baron O, Cassaing S, Percodani J, et al. Nucleotide sequencing for diagnosis of sinusal infection by Schizophyllum commune, an uncommon pathogenic fungus. J Clin Microbiol. 2006;44(8):3042-3.

22. Lorentz C, Rivier A, Debourgogne A, et al. Ethmoido-maxillary sinusitis caused by the basidiomycetous fungus Schizophyllum commune. Mycoses. 2012;55(2):8-12.

23. Pekic S, Arsenijevic VA, Gazibara MS, et al. What lurks in the sellar? Lancet. 2010;375(9712):432.

24. Perić A, Vojvodić D, Zolotarevski L, et al. Nasal polyposis and fungal Schizophyllum commune infection: a case report. Acta Med Austriaca. 2011; 54(2):83-6.

25. Premamalini T, Ambujavalli B T, Anitha S, et al. Schizophyllum commune a causative agent of fungal sinusitis: a case report. Case Rep Infect Dis. 2011; (10):821259.

26. Adhikary R, Joshi S. Comment on: Schizophyllum commune sinusitis in an immunocompetent host. Indian J Med Microbiol. 2012;30(2):249.

27. Clark S, Campbell CK, Sandison A, et al. Schizophyllum commune: an unusual isolate from a patient with allergic fungal sinusitis. J Infect. 1996;32(2):147.

28. Taguchi K, Oharaseki T, Yokouchi Y, et al. Allergic fungal sinusitis caused by Bipolaris spicifera and Schizophyllum commune. Med Mycol. 2007;45(6):559.

29. Matsuwaki $Y$, Ogawa $H$, Iwasaki $H$, et al. Allergic fungal rhinosinusitis (AFRS) caused by the basidiomycetous fungus Schizophyllum commune. OtoRhino-Laryngology Tokyo. 2013;56(6):8-18.

30. Ahmed MK, Ishino T, Takeno S, et al. Bilateral allergic fungal rhinosinusitis caused by Schizophillum commune and aspergillus Niger. A case report. Rhinology. 2009;47(2):217-21.

31. Shaw CL, Mccleave M, Wormald PJ. Unusual presentations of isolated sphenoid fungal sinusitis. J Laryngol Otol. 2000;114(114):385-8.

32. Sigler L, Bartley JR, Parr DH, et al. Maxillary sinusitis caused by medusoid form of Schizophyllum commune. J Clin Microbiol. 1999;37(10):3395-8.

33. Sa HS, Ko KS, Woo Kl, et al. A case of sino-orbital infection caused by the Schizophyllum commune. Diagn Microbiol Infect Dis. 2012;73(4):376-7.

34. Liu X, Zou H, Chen Q-J, et al. Allergic fungal sinusitis caused by Schizophyllum commune. World J Otorhinolary-Head Neck Surg. 2017; 3(1):59-63.

35. Yin $X$, Liang $Y$, Zeng $L$, et al. A case of sinusitis caused by Schizophyllum commune and Bacteria in acute Myelocytic leukemia. Clin Lab. 2015:61(11):1799.

36. Tomita K, Hashizume I, Kasamatsu N, et al. Allergic bronchopulmonary mycosis caused by Schizophyllum commune. Nihon Kyobu Shikkan Gakkai Zasshi. 1996;34(7):804-9.

37. Yamashina S. Case of allergic bronchopulmonary mycosis caused by Schizophyllum commune. Jpn J Antibiot. 1997;50(1):51-3.

38. Kamei $\mathrm{K}$, Unno H, Ito J, et al. Analysis of the cases in which Schizophyllum commune was isolated. Nihon Ishinkin Gakkai zasshi. 1999;40(3):175-81.

39. Yamasaki A, Nishimura K, Sano H, et al. A case of allergic bronchopulmonary mycosis caused by Schizophyllum commune. Allergy. 2002;51(5):439. 
40. Kawano T, Matsuse H, lida K, et al. Two cases of allergic bronchopulmonary mycosis caused by Schizophyllum commune in young asthmatic patients. Nihon Kokyūki Gakkai zasshi. 2003;41(3):233.

41. Amemiya $Y$, Shirai R, Tokimatsu I, et al. Allergic bronchopulmonary mycosis induced by Schizophyllum commune-case report and review of the literature. Nihon Kokyuki Gakkai zasshi. 2009;47(8):692.

42. Masunaga A, Morimoto K, Ando T, et al. Three cases of allergic bronchopulmonary mycosis due to Schizophyllum commune. Nihon Kokyuki Gakkai zasshi. 2010;48(12):912.

43. Ishiguro T, Takayanagi N, Saito A, et al. Allergic bronchopulmonary mycosis due to Schizophyllum commune and aspergillus fumigatus. Nihon Kokyuki Gakkai zasshi. 2011;49(8):612-8.

44. Ogawa H, Fujimura M, Takeuchi Y, et al. The definitive diagnostic process and successful treatment for ABPM caused by Schizophyllum commune: a report of two cases. Allergol Int. 2012;61(1):163-9.

45. Uruga $H$, Imafuku A, Hanada S, et al. A case of allergic bronchopulmonary mycosis caused by Schizophyllum commune presenting with hyperattenuated mucoid impaction. Nihon Kokyuki Gakkai Zasshi. 2010; 48(10):749-54

46. Ikushima S. Case of allergic bronchopulmonary mycosis caused by Schizophyllum commune. Jpn J Antibiot. 1997:50:47-9.

47. Nishimura K. Allergic bronchopulmonary mycosis caused by the Basidiomycetous fungus Schizophyllum commune[J]. Clin Infect Dis. 1994;18(3):305-9.

48. Tomita K, Hashizume I. Kasamatsu N, et al. [allergic bronchopulmonary mycosis caused by Schizophyllum commune][J]. Nihon Kyōbu Shikkan Gakkai Zasshi. 1996;34(7):804-9.

49. Seki M, Ohno H, Gotoh K, et al. Allergic bronchopulmonary mycosis due to co-infection with aspergillus fumigatus, and Schizophyllum commune[J]. Idcases. 2014;1(1):5-8.

50. Chowdhary A, Randhawa HS, Gaur SN, et al. Schizophyllum commune, as an emerging fungal pathogen: a review and report of two cases. Mycoses. 2013;56(1):1.

51. Amitani R, Nishimura K, Niimi A, et al. Bronchial mucoid impaction due to the Monokaryotic mycelium of Schizophyllum commune. Clin Infect Dis. 1996:22(1):146-8.

52. Miyazaki $Y$, Sakashita H, Tanaka T, et al. Mucoid impaction caused by monokaryotic mycelium of Schizophyllum commune in association with bronchiectasis. Intern Med. 2000;39(2):160-2.

53. Itou $Y$, Sasaki S, Watanabe $S$, et al. A case of mucoid impaction of bronchi (MIB) due to Schizophyllum commune. Nihon Kokyuki Gakkai Zasshi. 2001;39:266-70.

54. Ishiguro T, Takayanagi N, Tokunaga D, et al. Pulmonary Schizophyllum commune infection developing mucoid impaction of the bronchi. Yale $J$ Biol Med. 2007;80(3):105-11.

55. Ishiguro T, Takayanagi N, Harasaw K, et al. Mucoid impaction of the bronchi caused by Schizophyllum commune which developed after discontinuation of itraconazole administration. Nihon Kokyuki Gakkai zasshi. 2009;47(4):296.

56. Kato F, Kasamaatsu $\mathrm{N}$, Kasai $\mathrm{H}$, et al. A case of mucoid impaction of bronchi caused by Schizophyllum commune. J Jpn Soc Bronchology. 2012;34:38-43.

57. Sigler L, Maza LMDL, Tan G, et al. Diagnostic difficulties caused by a nonclamped Schizophyllum commune isolate in a case of fungus ball of the lung. J Clin Microbiol. 1995;33(8):1979-83.

58. Ogawa H, Fujimura M, Takeuchi Y, et al. Two cases of Schizophyllum asthma: is this a new clinical entity or a precursor of ABPM? Pulm Pharmacol Ther. 2011:24(5):559-62.

59. Kawayama T, Fujiki R, Rikimaru T, et al. Chronic eosinophilic pneumonia associated with, Schizophyllum commune. Respirology. 2003;8(4):529-31.

60. lizasa $T$, Kamei $K$, Chiyo $M$, et al. Colonization with Schizophyllum commune of localized honeycomb lung with mucus. Respiration. 2001;68(2):201-3.

61. Bulajic N, Cvijanovic V, Vukojevic J, et al. Schizophyllum commune, associated with bronchogenous cyst. Mycoses. 2006;49(4):343-5

62. Roan JN, Hsieh HY, Tsai HW, et al. Pulmonary nodules caused by Schizophyllum commune, after cardiac transplantation. J Infect. 2009; 58(2):164-7.

63. Chadeganipour M, Bonerje G, Nilipour S. Detection of antibodies in immunocompromised patients affected with pulmonary Schizophyllum infection. Clin Immunol. 2010;135(1):S75.
64. Tullio V, Mandras N, Banche G, et al. Schizophyllum commune: an unusual of agent bronchopneumonia in an immunocompromised patient. Med Mycol. 2009;46(46):735-8.

65. Matos T, Tomazin R, Battelino S. First report of otitis externa caused by Schizophyllum commune and review of the literature. Wien Klin Wochenschr. 2016;128(9-10):387-90.

66. Chan JFW, Teng JLL, Li IWS, et al. Fatal empyema Thoracis caused by Schizophyllum commune with cross-reactive Cryptococcal Antigenemia. J Clin Microbiol. 2014;52(2):683.

67. Chavez-Batista A, Maica JA, Singer R. Basidio-neuromycosis on man. Anals da Sociedade de Biologia de Pernambuco. 1955;13:52-60.

\section{Ready to submit your research? Choose BMC and benefit from:}

- fast, convenient online submission

- thorough peer review by experienced researchers in your field

- rapid publication on acceptance

- support for research data, including large and complex data types

- gold Open Access which fosters wider collaboration and increased citations

- maximum visibility for your research: over $100 \mathrm{M}$ website views per year

At BMC, research is always in progress.

Learn more biomedcentral.com/submissions 